\title{
RBS Characterization of Arsenic (III) Partitioning from Aqueous Phase into the Active Layers of Thin-Film Composite NF/RO Membranes
}

\author{
Baoxia $\mathrm{Mi}^{1}$, Benito J. Mariñas ${ }^{1, *}$, and David G. Cahill ${ }^{2}$ \\ ${ }^{1}$ Department of Civil and Environmental Engineering, ${ }^{2}$ Department of Materials Science and \\ Engineering, and ${ }^{1,2}$ Center of Advanced Materials for the Purification of Water with Systems, \\ University of Illinois at Urbana-Champaign, Urbana, IL 61801 \\ * Corresponding author [tel:+1-217-333-6961; fax:+1-217-333-6968; e-mail: marinas@uiuc.edu] \\ Journal: Environmental Science and Technology \\ Date Prepared: February 23, 2007 \\ Content Summary: five pages and four figures \\ Supporting Information
}




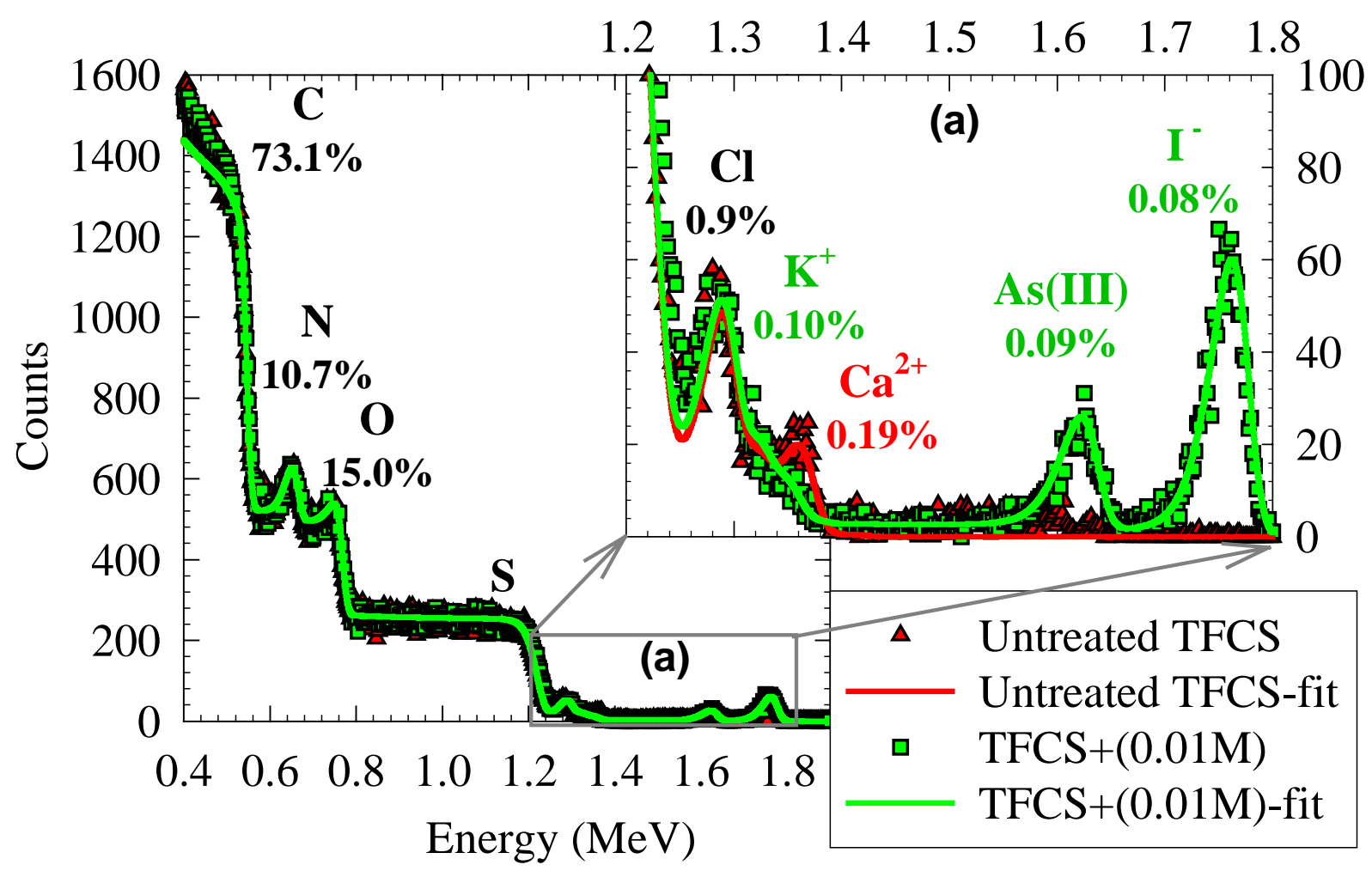

Fig. S1. RBS spectra of TFCS membrane samples. Red represents membrane before partitioning experiment, and green represents sample soaked in $0.01 \mathrm{M} \mathrm{H}_{3} \mathrm{AsO}_{3}$ and $0.01 \mathrm{M}$ KI solution at $\mathrm{pH}$ 6.5. The percentage values labeled on each peak are the concentration, $\varepsilon$, of each element in the membrane active layer. 


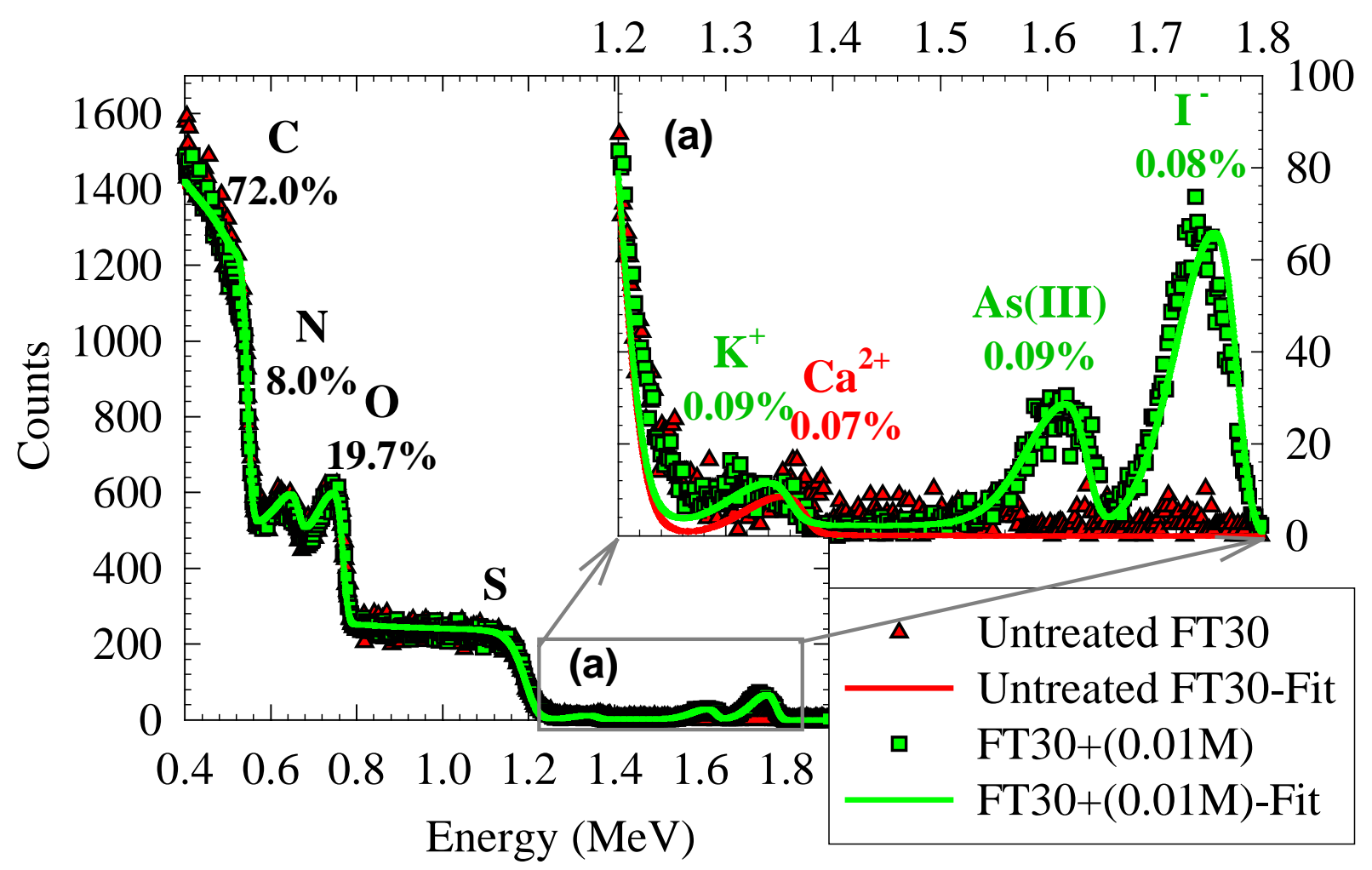

Fig. S2. RBS spectra of FT30 membrane samples. Red represents membrane before partitioning experiment, and green represents sample soaked in $0.01 \mathrm{M} \mathrm{H}_{3} \mathrm{AsO}_{3}$ and $0.01 \mathrm{M}$ KI solution at pH 6.5. The percentage values labeled on each peak are the concentration, $\varepsilon$, of each element in the membrane active layer. 


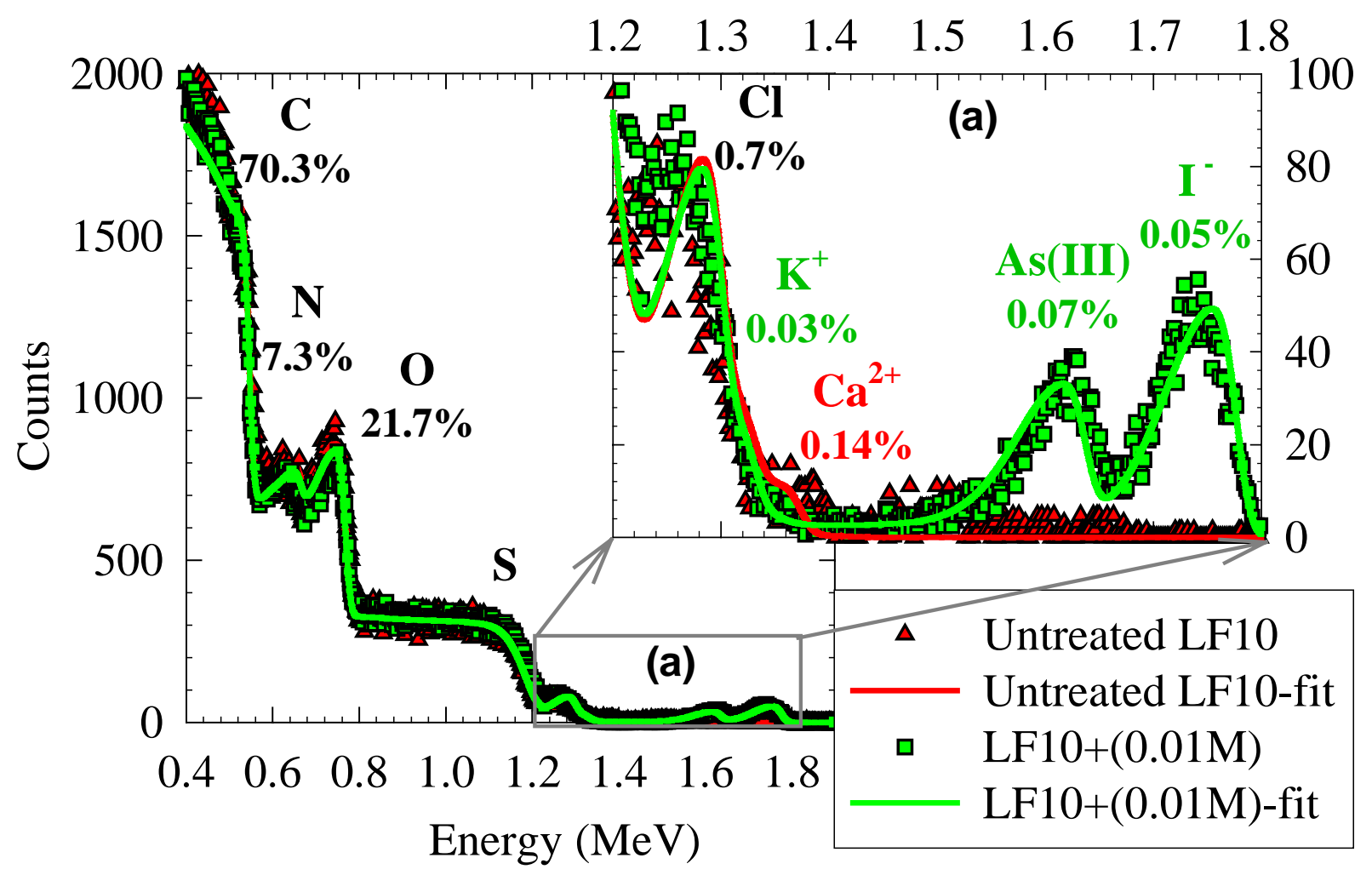

Fig. S3. RBS spectra of LF10 membrane samples. Red represents membrane before partitioning experiment, and green represents sample soaked in $0.01 \mathrm{M} \mathrm{H}_{3} \mathrm{AsO}_{3}$ and $0.01 \mathrm{M}$ KI solution at $\mathrm{pH}$ 6.5. The percentage values labeled on each peak are the concentration, $\varepsilon$, of each element in the membrane active layer. 


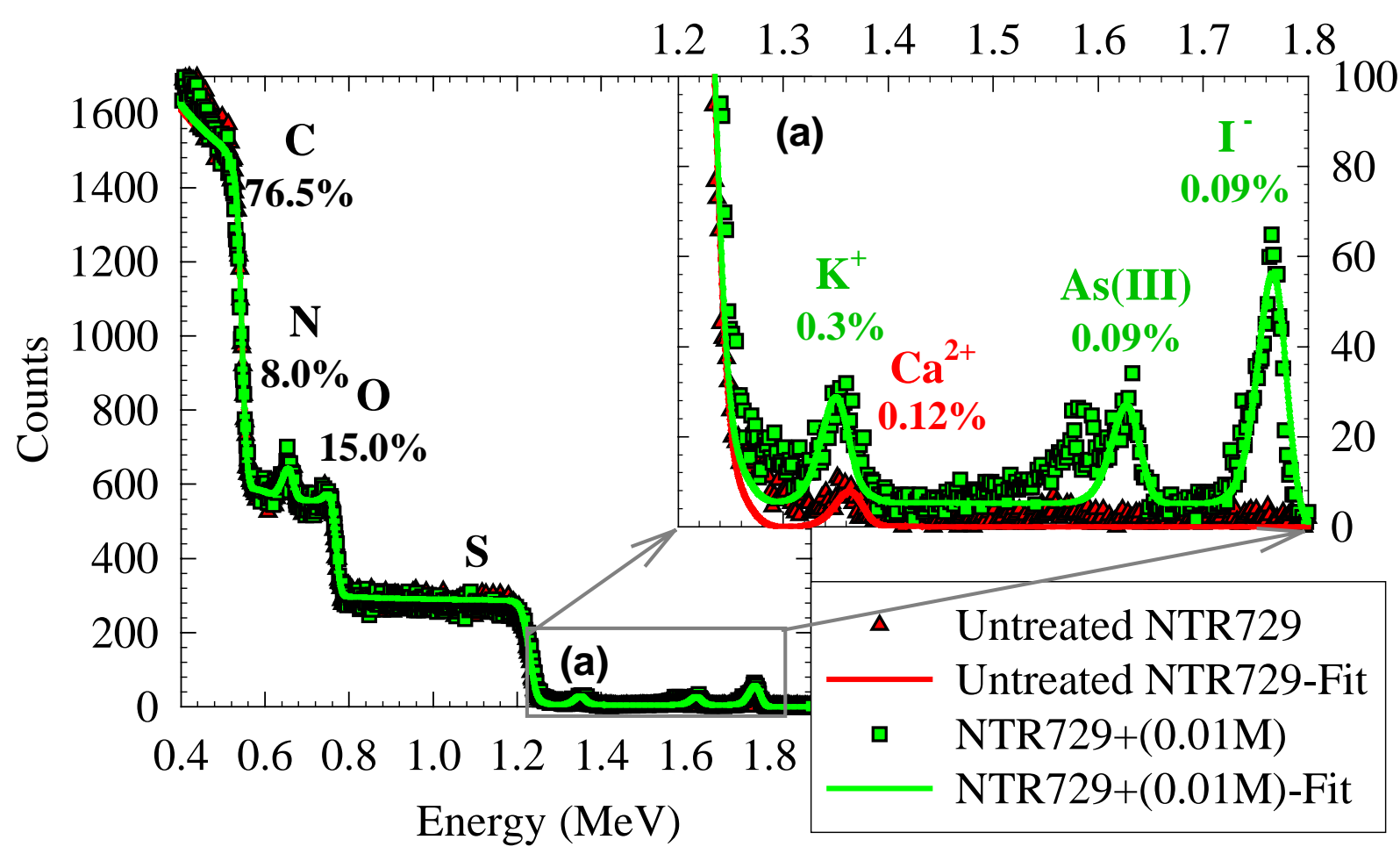

Fig. S4. RBS spectra of NTR729 membrane samples. Red represents membrane before partitioning experiment, and green represents sample soaked in $0.01 \mathrm{M} \mathrm{H}_{3} \mathrm{AsO}_{3}$ and $0.01 \mathrm{M}$ KI solution at pH 6.5. The percentage values labeled on each peak are the concentration, $\varepsilon$, of each element in the membrane active layer. 